\title{
О ТЕОРЕТИЧЕСКИХ АСПЕКТАХ ЦИФРОВОЙ ЭКОНОМИКИ
}

\author{
(c) 2021 Амурский А.А. \\ директор по развитию ООО «Элемент», Россия, Благовещенск \\ E-mail: amursaa@yandex.ru
}

В данной статье поднимаются общие вопросы развития цифровой экономики, с которыми столкнулись ведущие экономические державы мира. Автор выделяет основные аспекты естественных технологических преимуществ цифровой экономики: стимулирование сильного внутреннего рынка, развитие обрабатывающей промышленности, высвобождение потенциала внутреннего спроса и стимулирование строительства цифровой инфраструктуры. В статье также поднимается вопрос национальных преимуществ в международном сотрудничестве и конкуренции на основе развития цифровой экономики: создание глобальной цифровой торговой системы и перестройка глобального ландшафта технологических инноваций. Приведены также несколько концепций национального развития цифровой экономики, раскрыты их особенности и акценты.

Ключевые слова: цифровая экономика; внутренний рынок; цикл развития; цифровая инфраструктура; цифровая торговля.

\section{Введение}

В последние годы лидеры международного бизнеса неоднократно подчеркивают необходимость развития цифровой экономики в национальном и международном масштабах. Цифровая экономика КНР демонстрирует убедительные успехи и статус в национальной экономике продолжает повышаться. Большие данные, искусственный интеллект и блокчейнтехнологии уже проникают во все сферы экономики современного государства, а темпы технологических инноваций и скорость итеративного обновления продолжают ускоряться. Новые экономические модели, такие как сетевые совместные исследования и производство, крупномасштабная персонализированная индивидуализация, облачные офисы и беспилотная розничная торговля постепенно эволюционировали от зарождения к состоянию зрелости. Цифровые экономики отдельных стран уже достигли значительных практических результатов, поэтому исследования теоретических вопросов цифровой экономики также становятся все более актуальными.

Цифровая экономика и экономическое развитие

Внезапная вспышка эпидемии новой коронавирусной инфекции Covid-19 оказала серьезное влияние на функционирование мировой экономики, нарушив привычное функционирование глобальных производственных цепочек и цепочек поставок, что привело к нарушени- ям внутреннего национального производства и изменениям в структуре национального спроса. Одновременно с этим усилились позиции антиглобалистских движений и нового торгового протекционизма, так как экономическая глобализация и либерализация торговли понесли тяжелые потери, а внешний экспортный спрос большинства стран резко упал. Становится очевидным, что цифровая экономика постепенно стала ключевой движущей силой экономического роста с точки зрения ее технологических преимуществ и прикладной энергоэффективности.

(1) Цифровая экономика обладает естественными технологическими преимуществами, которые могут использовать потенциал сверхмасштабного рынка и внутреннего спроса.

Цифровая экономика - это новая экономическая форма, основанная на новом поколении цифровых технологий, таких как искусственный интеллект, блокчейн, большие данные и цифровые двойники. Она преодолевает внутренние временные и пространственные ограничения и традиционные промышленные границы, значительно сокращает промежуточные звенья и сокращает количество транзакций. В условиях цифровой экономики заметно снижается стоимость построения обширных связей и налаживания тесного сотрудничества между различными субъектами глобального рынка[1], а также стоимость цифровой экономической экосистемы с данными в качестве ключевого фактора производства, которые могут не только способ- 
ствовать использованию сверхмасштабных рыночных преимуществ, но и способствовать их развитию. Естественные технологические преимущества цифровой экономики выражаются в усилении сверхмасштабных рыночных преимуществ и потенциала внутреннего спроса, они в основном проявляются в четырех аспектах.

1) Стимулирование сильного внутреннего рынка.

На современном этапе, в том числе в экономике России, существует структурный дисбаланс в уровне развития между регионами, городскими и сельскими районами, а также между отраслями[2]. Развитие цифровой экономики может эффективно разрушить физические барьеры между регионами, городскими и сельскими районами и отраслями промышленности, способствовать круговому потоку различных ресурсов, таких как данные, информация, технологии, капитал и таланты, способствовать эффективной агломерации и точной стыковке различных производственных факторов, усилению региональной координации и межотраслевой интеграции.

2) Стимулирование развития обрабатывающей промышленности.

Российская производственная система отличается большим масштабом, однако до сих не стала ключевым узлом евразийской производственной цепочки и цепочки поставок. Увеличение промышленных прибылей в основном происходит за счет масштабного расширения, а не за счет инновационной деятельности. Добавленная стоимость обрабатывающей промышленности ведущих экономик мира в последние 10 лет имеет тенденцию к снижению. Для Китая это падение с 32\% до 28\%, для Японии - с $22 \%$ до $20 \%$, для России - с 16\% до 12\%. Германии после резкого падения в кризисном 2008 году удается держать данный показатель на уровне 21\%[3].

Развитие цифровых технологий будет способствовать постоянному ускорению цифровой, интеллектуальной и высокотехнологичной трансформации традиционных отраслей, будет способствовать формированию более специализированного, более глубокого и диверсифицированного разделения труда, а также будет способствовать постоянному расширению границ потенциальных производственных возможностей. Изменения технологической и экономической парадигмы открыли новый путь для модернизации обрабатывающей промышленности ведущих экономик мира, повышая конкурен- тоспособность национальной обрабатывающей промышленности.

3) Высвобождение потенциала внутреннего cnpoca.

Рассмотрим пример экономики КНР. Уровень конечного потребления в Китае, особенно уровень потребления домашних хозяйств, долгое время находился на низком уровне, что стало одним из основных препятствий, сдерживающих экономический рост Китая. На 18-м съезде КПК был провозглашен вектор на опережающее развитие национальных отраслей, которые ориентированы на внутреннее потребление. И такая политика показала свою эффективность, особенно в ситуации развития экономики в эпоху пандемии. Кроме того, за счёт переориентации экономики на внутреннее потребление Китай в последние годы стал масштабным рынком сбыта для соседних государств[4]. По оценкам экспертов, именно развитие цифровых технологий во многом способствовало глубоким изменениям в традиционной потребительской сфере и включило потребителей в систему национальных инноваций, что привело к реализации рядя высокоэффективных инновационных бизнесмоделей. Постоянно формирующиеся новые потребительские форматы, движимые цифровыми технологиями и ориентированные на решение проблем потребителей, реализуют многоуровневое и многоканальное высвобождение сверхмасштабного рыночного потребительского потенциала.

4) Стимулирование строительства цифровой инфраструктуры.

Процесс развития мировой экономики демонстрирует, что промышленная революция обязательно сопровождается итеративным обновлением инфраструктуры. В последние годы ведущие экономики мира значительно увеличили инвестиции в цифровую инфраструктуру. Укрепление цифровой инфраструктуры способствует полной интеграции факторов производства в различные экономических и социальных областях и становится множественным связующим звеном для консолидации и расширения внутренних и внешних производственных циклов.

(2) Цифровая экономика способствует активизации национальных преимуществ в международном сотрудничестве и конкуренции.

Благодаря инновационным достижениям цифровых технологий и распространению инте- 
грированных приложений, цифровая экономика постепенно стала важным двигателем мирового экономического роста, играя все более важную роль в глобальной торговой системе и оказывая глубокое влияние на реконструкцию мировой экономики. Цифровая экономика стала стратегическим высотным полигоном для международной конкуренции не только экономического, но и политического характера. Вектор на цифровизацию национальной экономики приведет к изменению в расстановке ключевых мировых игроков и появлению новых преимуществ для некоторых их них. Здесь важно отметить два аспекта.

1) Создание глобальной цүифровой торговой системы.

Цифровая торговля, основанная на цифровых технологиях и поддерживаемая цифровыми платформами, постепенно стала основной формой глобальной торговли в современном мире. Цифровая торговля реализует эффективный обмен услугами, физическими товарами и цифровыми продуктами за счет широкого применения информационных и коммуникационных технологий, делая торговую деятельность более либеральной. Она также помогает малым, средним и микропредприятиям во всем мире становиться полноправными участниками международных торговых процессов, предоставляет им возможность интегрировать систему глобальной цепочки создания стоимости. Быстрое развитие цифровой торговли способствует дальнейшему высвобождению производственного потенциала и цифровых дивидендов в глобальном масштабе, активизирует глубокие изменения в глобальном разделении труда и открыло новые возможности развития для развития глобальных торговых сетей.

Если опять обратиться к примеру Китая, то можно констатировать, что текущая цифровая торговля в данной стране демонстрирует стабильную тенденцию развития и огромный потенциал. Импорт и экспорт трансграничной электронной торговли Китая в 2020 году составил 1,69 трлн. юаней (261,5 млрд. долларов), что на $31,1 \%$ больше, чем в прошлом году, в то время как годовые темпы роста внешней торговли значительно отставали, составляя 1,9\%, согласно данным, опубликованным Главным таможенным управлением KHP (GAC). Международная В2В-платформа электронной коммерции Alibaba Group в своем годовом отчете отмечает, что в 2020 году объем транзакций увеличился на 101\% в долларовом выражении по сравнению с аналогичным периодом прошлого года, а количество заказов увеличилось вдвое. В 2020 году Tmall Global запустила около 1500 зарубежных маршрутов доставки, чтобы помочь зарубежным товарам поступать в Китай напрямую из более чем 40 стран и регионов. Платформа запустила свой первый прямой воздушный маршрут Китай-Европа для парфюмерии[5].

Ускорение создания глобальной цифровой торговой системы, опирающейся на цифровые торговые связи и беспрепятственное внутреннее и внешнее обращение, укрепляет позиции Китая в глобальной торговой системе и ускоряет его трансформацию из крупной торговой страны в лидера международной торговли.

2) Перестройка глобального ландшафта технологических инноваций.

В условиях распространения цифровых платформ потенциал приложений и их интеграционные эффекты значительно выросли. Мировые державы ставят технологические инновации в основу национального развития, придавая им особую важность и рассматривая цифровые технологии как основное условие для интеграции и развития различных промышленных технологий. В национальных экономиках доминирующее положение и ведущую роль стали занимать предприятия, ориентированные на технологических инновации, а национальные правительства с одной стороны стремятся всячески поощрять и поддерживать отечественные компании, занимающиеся цифровыми технологиями, разрабатывая национальные стратегии. Приведем ряд примеров.

- В декабре 2018 года правительство Австралии опубликовало свою стратегию цифровой экономики «Технологическое будущее Австралии» [6]. В Стратегии изложено видение того, как австралийцы должны наслаждаться повышенным качеством жизни и разделять возможности растущей, конкурентоспособной в мировом масштабе современной экономики, основанной на технологиях.

- В целях укрепления доверия между онлайн-потребителями и онлайн-трейдерами, а также для защиты конфиденциальности потребителей, правительство Канады опубликовало «Цифровую хартию Канады» [7], которая состоит из 10 базовых принципов, на которые должно опираться федеральное правительство в работе 
по вопросам цифровой трансформации и преобразования данных.

- Стратегия «Умная Япония» была разработана Министерством внутренних дел и связи Японии. Она прогнозирует экономический рост Японии и ее вклад в международное сообщество посредством информационных технологий. В стратегии сформулированы три основных видения[8]: 1) Создание нации, «опирающейся на знания и информацию. 2) Использование ИТ-технологий для создания комплексного решения сложных социальных проблем. 3) Оперативное реагирование на мировые тенденции.

- Национальная программа «Цифровая экономика Российской Федерации» была утверждена летом 2017 г. и рассчитана до 2024 года. Данная отечественная программа включает следующие несколько направлений развития: 1 . Нормативное регулирование цифровой среды. 2. Цифровая инфраструктура. 3. Человеческие ресурсы для цифровой экономики. 4. Кибербезопасность. 5. Цифровые технологии. 6. Цифровое госуправление. 7. Искусственный интеллект[9].

- 20 сентября 2018 г. правительство США опубликовало «Новую Стратегию кибербезопасности» с несколькими важными изменениями, которые призваны дать правительственным учреждениям и правоохранительным органам больше возможностей реагировать на киберпреступность и атаки национальных государств.

Как мы видим из приведенных примеров, национальные правительства по-разному видят и формулируют основные приоритеты развития национальной цифровой экономики, делая акценты на значимых для страны задачах цифровизации. Тем не менее, большинство стран мира признает цифровую экономику как новую реальность и демонстрируют высокую заинтересованность в развитии цифровой экономики со стороны государственных ведомств, научных кругов и промышленности.

\section{Выводы}

В постэпидемическую эпоху цифровая экономика обладает естественными технологическими преимуществами по сравнению с традиционными формами ведения национального хозяйства. Использование современных технологий (искусственный интеллект, блокчейн, большие данные, цифровые двойники и др.) в полной мере раскрывает сверхмасштабные рыночные преимущества национальных экономик и потенциал внутреннего спроса. В то же время с помощью новых технологий, новых форматов и новых бизнес-моделей цифровая экономика меняет международное сотрудничество, появляются новые лидеры. Для каждого современного государства становится очевидным, что сочетание новых технологий с традиционными конкурентными преимуществами дает дополнительную кинетическую энергию к национальному экономическому росту и является мощным стимулом для построения новой модели развития, а также гармонизации внутренних и международных циклов.

\section{Библиографический список}

1. Afonasova M.A., Panfilova E.E., Galichkina M.A. Social and Economic Background of Digital Economy: Conditions for Transition / European Research Studies Journal. 2018. Vol. XXI. Special Iss. 3. pp. 292-302.

2. Дзуцева Г.Н, Маргиев В. З. Структурные диспропорции в российской экономике на региональном уровне // Актуальные вопросы современной науки. - 2015.- № 44-2.- С.27-36

3. Уманский А. М. Обрабатывающая промышленность: добавленная стоимость в глобальном мире // Экономические науки. - 2019. - № 11(180). - С.80-86.

4. Иванов В., Свинова Е. Ускорение по-пекински: темпы роста экономики Китая превысили $18 \%$ в I квартале 2021 года. URL: https://russian.rt.com/business/article/853408-kitai-ekonomika-rost-rekord (дата обращения 30.05.2020).

5. Cross-border e-commerce contributes to China's foreign trade in 2020, with $31.1 \%$ annual growth amid pandemic URL: https://www.globaltimes.cn/page/202101/1212876.shtml (дата обращения 30.05.2020).

6. Australia's Tech Future. Delivering a strong, safe and inclusive digital economy. Australian Government, 2018.

7. Canada's Digital Charter: Trust in a digital world. Government of Canada, 2018.

8. Hishida Mitsuhiro. Smart japanict strategy - Achieving Economic Growth and Solving Social Issues with ICT. Ministry of Internal Affairs and Communications, 2018.

9. Цифровая экономика Российской Федерации. URL: https://digital.gov.ru/ru/activity/directions/858/ (дата обращения 30.05.2020).

10. National Cyber Strategy. URL: https:/www.whitehouse.gov/wp-content/uploads/2018/09/National-CyberStrategy.pdf (дата обращения 30.05.2020). 